\title{
Breaking C-C Bonds via Electrochemically Mediated Hydrogen Atom Transfer Reactions
}

\author{
Bing Yan¹, Changxia Shi², Gregg T. Beckham³, Eugene Y.-X. Chen², Yuriy Román-Leshkov¹,* \\ ${ }^{1}$ Department of Chemical Engineering, Massachusetts Institute of Technology, Cambridge, Massachusetts 02139, \\ United States \\ ${ }^{2}$ Department of Chemistry, Colorado State University, Fort Collins, Colorado 80523, United States \\ ${ }^{3}$ Renewable Resources and Enabling Sciences Center and the BOTTLE Consortium, National Renewable Energy Labor- \\ atory (NREL), Golden, Colorado 80402, USA
}

\begin{abstract}
Cleaving inert $\mathrm{sp}^{3}$-sp ${ }^{3}$ carbon-carbon (C-C) bonds selectively remains a major challenge in organic chemistry and a main bottleneck in the chemical upcycling of recalcitrant polyolefin waste. Here, we present an electrochemical strategy using redox mediators to activate and break C-C bonds at room temperature and ambient pressure. Specifically, we use $N$ hydroxyphthalimide (NHPI) as a redox mediator that undergoes electrochemical oxidation to form the phthalimide- $N$-oxyl (PINO) radical to initiate hydrogen atom transfer (HAT) reactions with benzylic C-H bonds. The resulting benzylic carbon radical is readily captured by molecular oxygen to form a peroxy radical that decomposes into oxygenated C-C bond-scission fragments. This indirect, mediated approach for $\mathrm{C}_{\mathrm{sp} 3}-\mathrm{C}_{\mathrm{sp} 3}$ bond cleavage reduces the oxidation potential by $>1.2 \mathrm{~V}$ compared to the direct oxidation of the substrate, thereby eliminating deleterious side reactions, such as solvent oxidation, that may occur at high potentials. Studies with a bibenzyl model compound revealed a bifurcated reaction pathway following the initial HAT step. At a bibenzyl conversion of $61.0 \%$, the C-C bond cleavage pathway generates benzaldehyde and benzoic acid products at 38.4\% selectivity, and the C-H bond oxygenation pathway leads to 1,2-diphenylethanone and benzil products at 39.2\% selectivity. Changes in reaction selectivity were investigated with various model compounds, including bibenzyl, 1,3-diphenylpropane, 1,4-diphenylbutane, and their derivatives. Product selectivity is correlated with the C-C bond strength of the reactant, with weaker $\mathrm{C}-\mathrm{C}$ bonds favoring the $\mathrm{C}-\mathrm{C}$ bond cleavage pathway. We also evaluated the mediated oxidation of oligomeric styrene $\left(M_{\mathrm{n}}=510 \mathrm{Da}, \mathrm{OS}_{510}\right)$ which were converted into oxygenated products. Lastly, proof-of-concept depolymerization of polystyrene (PS, $\sim 10,000 \mathrm{Da}$ ) into oxygenated monomers, dimers, and oligomers was demonstrated using NHPImediated oxidation.
\end{abstract}

\section{INTRODUCTION}

The selective cleavage of $\mathrm{sp}^{3}-\mathrm{sp}^{3}$ carbon-carbon (C-C) bonds is a major challenge in organic chemistry, and has recently emerged as a critical step in plastic waste deconstruction and biomass valorization. ${ }^{1-6}$ However, the inertness of the $\mathrm{C}_{\mathrm{sp} 3}-\mathrm{C}_{\mathrm{sp} 3}$ linkages hinders the selective and energy-efficient bond scission in these substrates. ${ }^{7-9}$ Indeed, $\mathrm{C}_{\mathrm{sp} 3}-\mathrm{C}_{\mathrm{sp} 3}$ bond activation is difficult due to several thermodynamic and kinetic constraints, ${ }^{10-14}$ including high bond dissociation energies (BDEs) of $\sim 90 \mathrm{kcal} \mathrm{mol}^{-1}, 10$ steric inaccessibility caused by surrounding $\mathrm{C}-\mathrm{H}$ bonds, and unfavorable orbital directionality towards cleavage which requires the rotation of two carbon $\mathrm{sp}^{3}$ orbitals. ${ }^{15}$ In some cases, C-C bond scission is facile, for example, for three- or four-membered cycloalkanes with high ring strain, for structures that introduce aromaticity upon cleavage (e.g., the elimination of a methyl group of ergosterol converts its cyclohexadiene ring into a phenyl ring), or for reactants that coordinate strongly to an active site (e.g., pincer-type compounds chelate to the catalyst metal center to direct the $\mathrm{C}-\mathrm{C}$ bond cleavage). ${ }^{10,15}$ However, the $\mathrm{C}-\mathrm{C}$ bonds prevalent in synthetic plastic waste typically do not fall into these special categories and necessitate aggressive reaction conditions for activation.
The thermodynamic and kinetic constraints for $\mathrm{C}_{\mathrm{sp} 3-}$ $\mathrm{C}_{\mathrm{sp} 3}$ bond cleavage have hampered the development of selective plastic depolymerization strategies. For example, thermochemical pathways used for plastic depolymerization, such as pyrolysis and thermal cracking, operate at temperatures $>400^{\circ} \mathrm{C}$ and suffer from low product selectivity. ${ }^{7}$ Reductive catalytic depolymerization strategies, such as hydrogenolysis and metathesis, improve the energy efficiency by ameliorating reactions conditions (temperatures $>200^{\circ} \mathrm{C}$ ), but require reductants such as high-pressure $\mathrm{H}_{2}$ and/or high-cost noble metal catalysts. ${ }^{8,16-19}$ Oxidative C-C bond cleavage generates oxygenated products as valuable chemicals, ${ }^{3}$ but the traditional approach requires bromine as a co-catalyst, ${ }^{20}$ impacting on the environment. These challenges together underscore the need to develop new strategies to selectively depolymerize plastic waste. 
a)

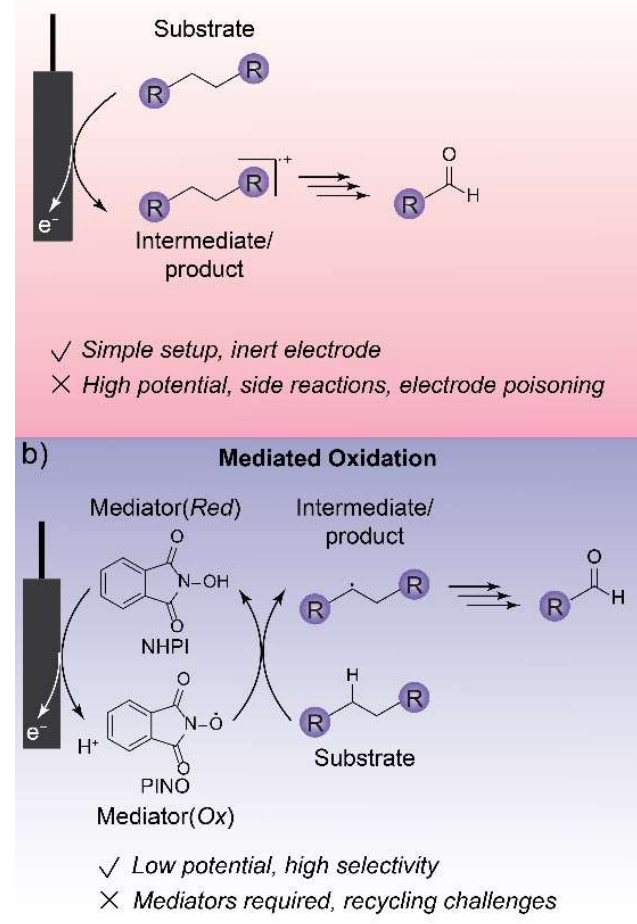

Figure 1. Schematic illustration of (a) direct and (b) mediated oxidation to cleave C-C bonds. $N$-hydroxyphthalimide (NHPI) is a mediator active for hydrogen atom transfer (HAT) reactions.

To this end, electrochemical oxidation presents a promising approach to activating and cleaving inert $\mathrm{C}-\mathrm{C}$ bonds under mild conditions. ${ }^{21-26}$ Such electrochemical approaches may be classified as direct or mediated. In a direct electrooxidation setup, the substrate undergoes electron transfer at the electrode. Similar to the harsh driving conditions of thermochemical processes, however, direct electrooxidation often requires highly anodic potentials in order to overcome the sluggish $\mathrm{C}-\mathrm{C}$ bond activation kinetics, which can lead to side reactions such as solvent oxidation (Figure 1a). ${ }^{27,28}$ Alternatively, in mediated electrooxidation, a redox-active species can be used to mediate the process indirectly by first undergoing oxidation at the electrode, then selectively oxidizing the substrate of interest in solution, and lastly regenerating at the electrode to start the cycle over (Figure 1b). Importantly, mediators provide an additional design handle by which to facilitate the kinetics of electron transfer. Indeed, the mediator can be designed to undergo rapid electron transfer at the electrode surface, significantly lowering the oxidation potential necessary to drive substrate conversion. Furthermore, mediators can be engineered to react with the substrate selectively, thus eliminating many side reactions. Thus, in principle, mediated electrooxidation could enable selective $\mathrm{C}-\mathrm{C}$ bond cleavage under mild conditions.

A large number of redox mediators have been explored in electrocatalysis, including organic molecules, transition metal complexes, and inorganic salts, which exhibit a wide range of redox potentials and reactivity. ${ }^{27-29}$ For example, 2,2,6,6-tetramethylpiperidine $N$-oxyl (TEMPO) mediates hydride transfer for alcohol oxidation; ${ }^{19}$ transition metal salts mediate oxygen transfer or electron transfer to oxidize olefins and aromatics; ${ }^{29}$ and $\mathrm{Ni}$ - and Co-salen complexes mediate electron transfer for the reductive cyclization of unsaturated aldehydes, ketones, and esters. ${ }^{29}$ In addition, $N$ hydroxyphthalimide (NHPI) is well-known to mediate hydrogen atom transfer (HAT), and is readily oxidized at a carbon electrode into the phthalimide- $N$-oxyl (PINO) radical. ${ }^{30-}$ ${ }^{34}$ In turn, PINO is highly adept at benzylic C-H HAT to return to its reduced form, NHPI, and complete one catalytic cycle (Figure 1b).

In view of the efficient redox kinetics of NHPI/PINO and selective benzylic hydrogen atom abstraction, we hypothesize that NHPI/PINO could selectively mediate $\mathrm{C}_{\mathrm{sp} 3}-\mathrm{C}_{\mathrm{sp} 3}$ bond cleavage with application to plastic waste depolymerization. Here, we employ NHPI to catalyze HAT reactions that activate benzylic $\mathrm{C}-\mathrm{C}$ bonds towards bond scission by converting a $\mathrm{C}-\mathrm{H}$ bond into a carbon radical (Figure 1b). The resulting carbon radical is susceptible to further oxidation (e.g., in the presence of molecular oxygen) to form a peroxy species that decomposes into products with cleaved $\mathrm{C}-\mathrm{C}$ bonds. We demonstrate the viability of this approach by performing the NHPI-mediated electrochemical C-C bond cleavage of bibenzyl, 1,3-diphenylpropane, 1,4-diphenylbutane, and their derivatives. We also evaluate the mediated oxidation of oligomeric styrene $\left(M_{\mathrm{n}}=510 \mathrm{Da}, \mathrm{OS}_{510}\right)$. Moreover, as a proof-of-concept, we implement our strategy to depolymerize polystyrene (PS, $10,000 \mathrm{Da}$ ) into oxygenated monomers, dimers, and oligomers.

\section{RESULTS AND DISCUSSION}

Cyclic voltammetry (CV) confirms that NHPI mediates substrate oxidation. Cyclic voltammetry (CV) was used to study the redox behavior of NHPI. The voltamograms were recorded at $10 \mathrm{mV} \mathrm{s}^{-1}$ in $0.1 \mathrm{M}$ $\mathrm{LiBF}_{4} /$ acetonitrile electrolyte consisting of $10 \mathrm{mM}$ NHPI. The positions of the oxidative and reductive peak potentials at 1.67 and $0.98 \mathrm{~V}$ vs $\mathrm{Ag} / \mathrm{AgCl}$, respectively, confirmed the quasi-reversibility of the PINO/NHPI redox couple (Figure S1, black trace). The addition of $0.1 \mathrm{M}$ pyridine shifted the oxidation and reduction potentials negatively to 0.86 and $0.79 \mathrm{~V}$ vs $\mathrm{Ag} / \mathrm{AgCl}$, respectively (Figure S1, red trace), indicating that the PINO/NHPI redox couple is sensitive to the electrolyte basicity since protons are a product of NHPI oxidation (Figure 1b).

Previous studies have suggested that PINO decomposes in alkaline media. ${ }^{30,35}$ To evaluate the stability of PINO, we gradually dosed acetic acid (HOAc) at $0.02 \mathrm{M}$ increments up to a concentration of $0.10 \mathrm{M}$. After each dose of HOAc, we recorded a CV scan (Figure S1, blue trace and Figure S2a) and measured the potential separation between the oxidative and reductive peaks (Figure $\mathbf{S} \mathbf{2} \mathbf{b}$ ) to assess the reversibility of a redox couple. We note that a reversible reaction exhibits a $57 \mathrm{mV}$ separation between the oxidative and reductive features at room temperature, and this value increases when the reaction becomes increasingly irreversible. ${ }^{36}$ For the PINO/NHPI couple, the oxidative-reductive peak separation decreased from 93.8 to $76.3 \mathrm{mV}$ with increasing HOAc concentration from 0 to $0.1 \mathrm{M}$, indicating that the redox couple becomes more reversible when the electrolyte turns more acidic. These results suggest that the stability of PINO improves in an HOAc-pyridine buffered electrolyte compared to the pyridine-only electrolyte and agree with bulk electrolysis data (see below). Therefore, an 
HOAc-pyridine buffered electrolyte was used in all experiments unless otherwise stated.

Bibenzyl was used as a model compound to evaluate the catalytic efficacy of PINO. After adding $50 \mathrm{mM}$ bibenzyl to the electrolyte, the PINO reductive feature disappeared and the oxidative current increased compared to that obtained in the absence of bibenzyl (Figure 2, black and red traces), confirming that PINO oxidized bibenzyl. Notably, the potential required to reach a current of $1.0 \mathrm{~mA}$ (denoted here as the onset potential) for the NHPI-mediated bibenzyl oxidation was $0.80 \mathrm{~V}$, a value $1.26 \mathrm{~V}$ less positive than that for bibenzyl direct oxidation (2.06 V) in the absence of mediators (Figure 2, grey trace). The small anodic feature at $\sim 1.5 \mathrm{~V}$ in bibenzyl direct oxidation is a pre-activation of the substrate.

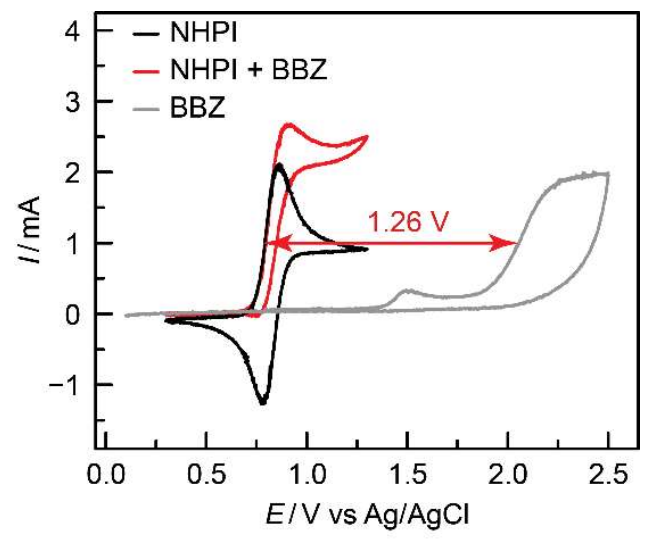

Figure 2. Cyclic voltammetry (CV) plots of $10 \mathrm{mM}$ PINO/NHPI redox couple in the absence (black) and presence of $50 \mathrm{mM}$ bibenzyl (red). The grey trace denotes bibenzyl direct oxidation in the absence of the NHPI mediator. At $1 \mathrm{~mA}$, the NHPImediated bibenzyl oxidation requires a potential of $1.26 \mathrm{~V}$ less positive than that of direct bibenzyl oxidation. All CVs were recorded at $10 \mathrm{mV} \mathrm{s}^{-1}$ in $0.1 \mathrm{M} \mathrm{LiBF}_{4} /$ acetonitrile electrolyte containig $0.1 \mathrm{M}$ pyridine $+\mathrm{HOAc}$.

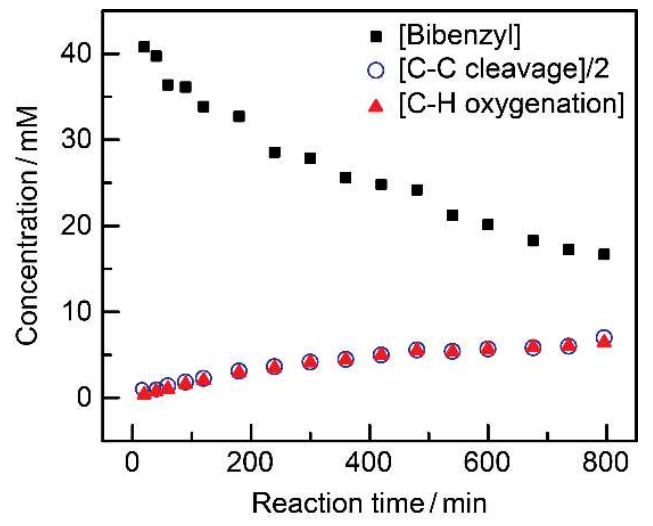

Figure 3. Concentration profiles of bibenzyl, C-C bond cleavage products (benzaldehyde and benzoic acid), and $\mathrm{C}-\mathrm{H}$ oxygenation products (1,2-diphenylethanone and benzil) during NHPImediated bibenzyl oxidation.
Bulk electrolysis suggests a bifurcated reaction pathway. Bulk bibenzyl electrolysis studies were performed to gain insights into the oxidation reaction pathways. The experiments were carried out in an H-shaped glass cell with working and counter chambers separated by a Nafion membrane (Figure S3). A constant current (typically $2 \mathrm{~mA}$ ) was applied up to a potential of $1.5 \mathrm{~V} \mathrm{vs} \mathrm{Ag} / \mathrm{AgCl}$ marking the onset of PINO oxidation. Figure S4 shows a representative chronopotentiometry trace for these experiments. A steady increase of potential throughout the electrolysis was observed, likely due to the irreversible decomposition of PINO, 27,37-39 which reduces the concentration of the NHPI/PINO mediator in the solution. On average, each molecule of NHPI carries out 7.5 turnovers before undergoing decomposition based on the charge passed during the electrolysis (see the Supporting Information for calculation details). Products for a typical NHPI-mediated bibenzyl oxidation reaction were identified by gas chromatographymass spectrometry (GC-MS) and quantified by gas chromatography-flame ionization detector (GC-FID) (Figures S57). Two types of products were observed: 1) C-C bond cleavage products (i.e., benzaldehyde and benzoic acid) and 2) C$\mathrm{H}$ oxygenation products (i.e., 1,2-diphenylethanone and benzil). During the reaction, the electrolyte was sampled and the reaction progress was monitored at regular intervals. The concentration profiles of the $\mathrm{C}-\mathrm{C}$ bond cleavage products (concentrations were divided by two to account for one molecule of bibenzyl generating two molecules of benzaldehyde or benzoic acid) (Figure 3, blue open circle) and $\mathrm{C}-\mathrm{H}$ bond oxygenation products (Figure 3, red solid triangle) overlap with each other, suggesting that the products originate from a single intermediate that decomposes into either product family with equal probability. Based on these results, we hypothesize that a bifurcated reaction pathway exists (Scheme 1) wherein: 1) bibenzyl transfers a benzylic $\mathrm{C}-\mathrm{H}$ to the electrochemically generated PINO; 2) the resulting benzylic carbon radical is captured by $\mathrm{O}_{2}$ to afford a peroxy radical; and 3 ) the peroxy radical decomposes in two parallel pathways, one involving $\mathrm{C}-\mathrm{C}$ bond cleavage and the other $\mathrm{C}-\mathrm{H}$ bond oxygenation. 


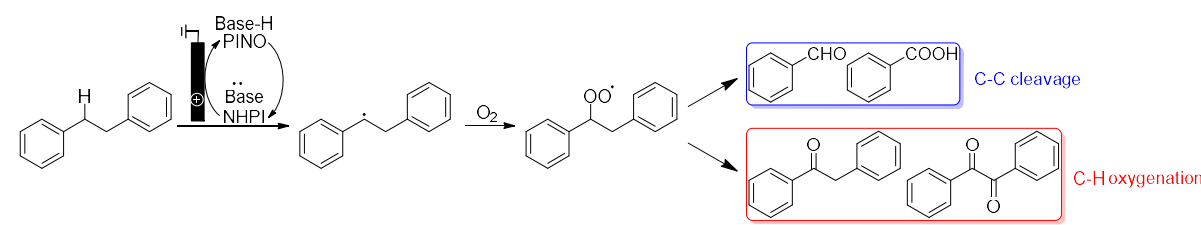

Scheme 1. A bifurcated pathway of C-C bond cleavage and C-H oxygenation follows PINO induced HAT and $\mathrm{O}_{2}$ adduction.

Table 1. Optimization of preparative bibenzyl oxidation conditions

\begin{tabular}{|c|c|c|c|c|c|c|}
\hline Entry & NHPI (mol\%)a & Base (equiv) ${ }^{\mathrm{b}}$ & Electrolyte & $\begin{array}{c}\text { Conversionc } \\
(\%)\end{array}$ & $\begin{array}{l}\text { Selectivity C-C } \\
\text { cleavaged }(\%)^{\text {d }} \%\end{array}$ & $\begin{array}{c}\text { Selectivity C-H } \\
\text { oxygenation }^{\mathrm{e}}(\%)\end{array}$ \\
\hline 1 & $2 \%$ & $\begin{array}{c}\text { Pyridine (Py), } \\
\text { HOAc }(2,2)\end{array}$ & $\mathrm{LiBF}_{4}$ & 16.3 & 17.8 & 19.6 \\
\hline 2 & $10 \%$ & $\begin{array}{c}\text { Py, HOAc }(2, \\
2)\end{array}$ & $\mathrm{LiBF}_{4}$ & 39.5 & 38.7 & 42.3 \\
\hline 3 & $20 \%$ & $\begin{array}{c}\text { Py, HOAc }(2, \\
2)\end{array}$ & $\mathrm{LiBF}_{4}$ & 61.0 & 38.4 & 39.2 \\
\hline 4 & $40 \%$ & $\begin{array}{c}\text { Py, HOAc }(2, \\
2)\end{array}$ & $\mathrm{LiBF}_{4}$ & 82.3 & 31.5 & 29.4 \\
\hline 5 & $\left(\mathrm{Cl}_{4} \mathrm{NHPI}\right) 20 \%$ & $\begin{array}{c}\text { Py, HOAc }(2, \\
2)\end{array}$ & $\mathrm{LiBF}_{4}$ & 64.4 & 32.1 & 35.6 \\
\hline 6 & (di-NHPI) $20 \%$ & $\begin{array}{c}\mathrm{Py}, \mathrm{HOAc}(2, \\
2)\end{array}$ & $\mathrm{LiBF}_{4}$ & 44.0 & 23.7 & 23.5 \\
\hline 7 & $20 \%$ & Py (2) & $\mathrm{LiBF}_{4}$ & 61.9 & 29.7 & 31.5 \\
\hline 8 & $20 \%$ & $\begin{array}{c}\text { Py, HOAc }(4, \\
4)\end{array}$ & $\mathrm{LiBF}_{4}$ & 60.2 & 30.6 & 30.1 \\
\hline 9 & $20 \%$ & $\begin{array}{l}\text { Py, HOAc }(10, \\
10)\end{array}$ & $\mathrm{LiBF}_{4}$ & 58.3 & 25.7 & 24.7 \\
\hline 10 & $20 \%$ & $\begin{array}{c}\mathrm{Py}, \mathrm{HClO}_{4}(2, \\
0.4)\end{array}$ & $\mathrm{LiBF}_{4}$ & 52.1 & 25.9 & 29.6 \\
\hline 11 & $20 \%$ & $\begin{array}{c}\mathrm{Py}, \mathrm{HClO}_{4}(2, \\
1)\end{array}$ & $\mathrm{LiBF}_{4}$ & 8.2 & 34.1 & 34.1 \\
\hline 12 & $20 \%$ & $\begin{array}{l}\text { 2,6-Lutidine } \\
\text { (2) }\end{array}$ & $\mathrm{LiBF}_{4}$ & 66.5 & 28.9 & 29.5 \\
\hline 13 & $20 \%$ & $\mathrm{KHCO}_{3}(2)$ & $\mathrm{LiBF}_{4}$ & 46.5 & 38.3 & 23.0 \\
\hline 14 & $20 \%$ & $\begin{array}{c}\text { Py, HOAc }(2, \\
2)\end{array}$ & $\mathrm{LiClO}_{4}$ & 65.4 & 32.4 & 33.5 \\
\hline 15 & $20 \%$ & $\begin{array}{c}\text { Py, HOAc }(2, \\
2)\end{array}$ & TBAPF $_{6}$ & 74.0 & 18.1 & 20.8 \\
\hline
\end{tabular}

aThe mole percentage of NHPI is relative to bibenzyl concentration, $50 \mathrm{mM}$.

bThe equivalent of pyridine and acid is relative to bibenzyl concentration, $50 \mathrm{mM}$.

${ }^{c}$ Conversion $=\frac{[\text { bibenzyl }]_{\text {initial }}-[\text { bibenzyl }] \text { final }}{[\text { bibenzyl }]_{\text {initial }}} \times 100 \%$.

${ }^{\mathrm{d}}$ Selectivity $\mathrm{C}-\mathrm{C}$ cleavage $=\frac{[\text { benzaldehyde }]+[\text { benzoic acid }]}{2\left([\text { bibenzyl }]_{\text {initial }}-[\text { bibenzyl }]_{\text {final }}\right)} \times 100 \%$.

eSelectivity C - H oxygenation $=\frac{[1,2-\text { diphenyleth }]+[\text { benzil }]}{[\text { bibenzyl }]_{\text {initial }}-[\text { bibenzyl }] \text { final }} \times 100 \%$.

Bulk electrolysis condition optimization. We investigated the effects of multiple factors on the conversion of bibenzyl and the product selectivity including NHPI amount, substituents on the NHPI phenyl ring, media basicity, electrolyte types, solvent, $\mathrm{O}_{2}$ partial pressure, temperature, and oxidation current to explore optimal conditions for bulk electrolysis. The results are summarized in Table 1 and Tables S1-5.
Entries 1-4 in Table 1 show the effects of increasing NHPI amount from 2 to $40 \mathrm{~mol} \%$ with respect to bibenzyl. Higher NHPI concentrations improved bibenzyl conversion, but product selectivity decreased when NHPI was increased from 10 to $40 \mathrm{~mol} \%$. We also tested two NHPI derivatives, 3,4,5,6-tetrachloro- $N$-hydroxyphthalimide ( $\left.\mathrm{Cl}_{4} \mathrm{NHPI}\right)$ and $N, N$ '-dihydroxypyromellitimide (di-NHPI) as alternative re- 
dox mediators (Table 1, Entry 5-6). The thermodynamic redox potential of $\mathrm{Cl}_{4} \mathrm{NHPI}$ is $0.88 \mathrm{~V}$ vs $\mathrm{Ag} / \mathrm{AgCl}$ (obtained from CV, Figure S8), which is $60 \mathrm{mV}$ more positive than that of NHPI (0.82 V vs Ag/AgCl, Figure 2), making the PINO radical of $\mathrm{Cl}_{4}$ NHPI more reactive than that of NHPI. ${ }^{40}$ Although higher bibenzyl conversions were observed, $\mathrm{Cl}_{4} \mathrm{NHPI}$ generated lower product selectivity due to higher rates of deleterious side reactions. For di-NHPI, its PINO radical is significantly less stable than PINO. ${ }^{39}$ As a result, the faster decomposition of di-NHPI led to both lower bibenzyl conversion and product selectivity. We also tested other types of $N$-oxyl radicals including aminoxyls (e.g., TEMPO) and iminoxyls (e.g., oxime radicals) (Table S1). However, none of them catalyzed the HAT of bibenzyl. We surmise the lack of reactivity is partly due to a mismatch of BDEs between the $\mathrm{C}-\mathrm{H}$ bonds of bibenzyl and the NO-H bond of the radical precursors, ${ }^{41}$ although steric effects may also play a role.

The effects of electrolyte basicity on NHPI-mediated bibenzyl oxidation were investigated by using varying equimolar mixtures of pyridine and HOAc (Table 1, Entries 3,8 , and 9 ) or only two equivalents of pyridine (Table 1, Entry 7). The latter featured lower product selectivity likely due to side reactions of the bibenzyl radical intermediate in the absence of HOAc. Interestingly, when increasing pyridine and HOAc amounts, both conversion and selectivity decreased. These results suggest that a high concentration of pyridine suppresses bibenzyl conversion even in the presence of HOAc.

Using perchloric acid $\left(\mathrm{HClO}_{4}\right)$ as a stronger acid than HOAc resulted in drastically reduced conversions (Table 1, Entry 10 and 11). This is attributed to the positive shift of the PINO/NHPI redox potential with increasing acidity of the electrolyte, which resulted in little bibenzyl conversion at potentials lower than $1.5 \mathrm{~V}$ vs $\mathrm{Ag} / \mathrm{AgCl}$.

Finally, the effect of basicity was investigated by switching from pyridine to 2,6-lutidine (Table 1, Entry 12) or potassium bicarbonate $\left(\mathrm{KHCO}_{3}\right.$, Table 1, Entry 13). 2,6Lutidine (conjugated acid $\mathrm{p} K_{\mathrm{a}}=6.72$ ) is a stronger base than pyridine (conjugated acid $\mathrm{p} K_{\mathrm{a}}=5.25$ ), resulting in a higher conversion (Entry 12 vs Entry 7). Nevertheless, the methyl groups of 2,6-lutidine are susceptible to PINO HAT as a side reaction, which adds difficulties in product analysis. On the other hand, $\mathrm{KHCO}_{3}$, generated lower conversion compared to pyridine - an effect that is partly due to the poor solubility of $\mathrm{KHCO}_{3}$ in acetonitrile, but the selectivity of $\mathrm{C}-\mathrm{C}$ bond cleavage was improved. Investigations into why $\mathrm{KHCO}_{3}$ promotes $\mathrm{C}-\mathrm{C}$ bond cleavage are currently underway.

In terms of electrolyte types, we observed that $\mathrm{LiBF}_{4}$ (Table 1, Entry 3) and $\mathrm{LiClO}_{4}$ (Table 1, Entry 14) led to similar bibenzyl conversion and product selectivity, while TBAPF $_{6}$ (Table 1, Entry 15) resulted in a higher bibenzyl conversion but much lower product selectivity. We hypothesize that $\mathrm{Li}^{+}$may be able to stabilize PINO and/or bibenzyl oxidation intermediates. ${ }^{42}$

To gain insight into the role of solvent on bibenzyl oxidation, we carried out reactions in acetonitrile, acetone, and $\mathrm{N}, \mathrm{N}$-dimethylformamide (DMF) solvents (Table S2). DMF is susceptible to PINO HAT and thus eliminated bibenzyl activity. In acetone, the conversion of bibenzyl was only half of that in acetonitrile, but product selectivity was improved. The suppressed conversion in acetone is likely because acetone facilitates the formation of an NHPI-solvent adduct via hydrogen bonding (e.g., NO-H'-solvent), and this adduct is less prone to electrochemical oxidation. ${ }^{31,37}$ Therefore, we posit acetone drives the equilibrium further to the NHPIsolvent adduct and results in a lower conversion of bibenzyl. Similarly, the solvated NHPI is less prone to deleterious side reactions with bibenzyl radical intermediates, leading to higher product selectivity.

The effects of $\mathrm{O}_{2}$ partial pressure were evaluated because $\mathrm{O}_{2}$ captures the benzylic radical to form the peroxy radical preluding product formation. Specifically, we performed bulk electrolysis in $\mathrm{N}_{2}, 1 \% \mathrm{O}_{2}$ balanced by $\mathrm{He}$, air, and pure $\mathrm{O}_{2}$ (Table S3). In an $\mathrm{N}_{2}$ atmosphere, 8.1\% of bibenzyl was converted, but no products of $\mathrm{C}-\mathrm{C}$ bond cleavage or $\mathrm{C}-\mathrm{H}$ bond oxygenation were detected. This result agrees with the proposed reaction pathway involving a peroxy radical intermediate. Increasing the $\mathrm{O}_{2}$ partial pressure from 0.01 to $1 \mathrm{~atm}$, improved bibenzyl conversion slightly (using $10 \mathrm{~mol} \% \mathrm{NHPI}$ ), but the product selectivity dramatically. Similar effects were also observed for $20 \mathrm{~mol} \%$ NHPI. However, $\mathrm{O}_{2}$ promotion was less pronounced for $2 \mathrm{~mol} \% \mathrm{NHPI}$ where product selectivity even decreased slightly when increasing $\mathrm{O}_{2}$ partial pressure from 0.21 to $1 \mathrm{~atm}$. We attribute the $\mathrm{O}_{2}$ promotion effects, especially at high NHPI concentrations (10 and $20 \mathrm{~mol} \%$ ), to the improved mass transport of $\mathrm{O}_{2}$ to the benzylic radical intermediate. At low NHPI concentration, however, the reaction becomes limited by the HAT from bibenzyl to PINO or the oxidation of NHPI to PINO. ${ }^{27,37,38,43}$

The effects of temperature and oxidation current indicate a compromise between reaction rates and PINO stability. While a higher temperature or a larger oxidation current gives rise to faster reactions, PINO decomposition is also faster, leading to a lower bibenzyl conversion and product selectivity. For example, the selectivity at $25^{\circ} \mathrm{C}$ was higher than that at 50 or $2{ }^{\circ} \mathrm{C}$, and the conversion at $25^{\circ} \mathrm{C}$ was higher than $50{ }^{\circ} \mathrm{C}$ but slightly lower than $2^{\circ} \mathrm{C}$ ( Table S4, using $10 \mathrm{~mol} \% \mathrm{NHPI}$ ). Similarly, the conversion and the selectivity first improved with increasing oxidation current from 1 to $2 \mathrm{~mA}$, but then dropped from 2 to $5 \mathrm{~mA}$ (Table S5). Consequently, both the reaction rate and PINO stability should be considered when optimizing reaction temperature and oxidation current.

Taken together, all these experiments established the optimal NHPI-mediated oxidation conditions to achieve high conversion and selectivity: $20 \mathrm{~mol} \% \mathrm{NHPI}, 0.1 \mathrm{M}$ pyridine, $0.1 \mathrm{M} \mathrm{HOAc}$, $0.1 \mathrm{M} \mathrm{LiBF}_{4} /$ acetonitrile electrolyte, $1 \mathrm{~atm} \mathrm{O}_{2}$, room temperature, and an oxidation current of $2 \mathrm{~mA}$. We then applied these reaction conditions to oxidize several model compounds and polystyrene samples.

Selectivity of C-C bond cleavage is determined by the $\mathrm{C}-\mathrm{C}$ bond strength. We observed identical selectivity values of $\mathrm{C}-\mathrm{C}$ bond cleavage and the $\mathrm{C}-\mathrm{H}$ bond oxygenation for bibenzyl oxidation (Figure 3, Scheme 1), thus implicating a bifurcated reaction pathway. To investigate the structural factors that affect the selectivity of C-C bond cleavage, a number of model substrates were evaluated, all of which contain two phenyl rings but differ in the length of alkyl chains separating the rings and in the substituents on the alkyl chains. These structural variations are expected to alter the $\mathrm{C}-\mathrm{C}$ bond strength and the reactivity of the $\mathrm{C}-\mathrm{H}$ bond, thus influencing C-C bond cleavage selectivity. Figures S14S15 show the representative chronopotentiometry traces 
of the bulk electrolysis, Table 2 lists the conversion, yields, and selectivity, and Figure 4, Figure S16 and Table S6 illustrate the product distribution for these substrates. The products were characterized by GC-MS, GC-FID, and highperformance liquid chromatography (HPLC).

Table 2. Results for the NHPI-mediated C-C bond cleavage and C-H bond oxygenation of benzylic substrates.

\begin{tabular}{|c|c|c|c|c|}
\hline Entry & Substrate & $\begin{array}{c}\text { Conversion } \\
(\%)\end{array}$ & $\begin{array}{c}\text { Selectivity C-C } \\
\text { cleavage (\%) }\end{array}$ & $\begin{array}{c}\text { Selectivity C-H } \\
\text { oxygenation (\%) }\end{array}$ \\
\hline 1 & & 61.0 & 38.4 & 39.2 \\
\hline 2 & & 100 & 7.2 & 61.3 \\
\hline 3 & & 80.7 & 0.4 & 61.3 \\
\hline 4 & & 26.5 & 27.5 & 43.8 \\
\hline 5 & & 14.8 & 0.2 & 0.0 \\
\hline 6 & & 4.2 & 0.5 & 1.0 \\
\hline 7 & & 11.7 & 6.8 & 0.0 \\
\hline 8 & & 71.9 & 13.5 & 47.6 \\
\hline 9 & & 96.2 & 7.8 & 59.9 \\
\hline 10 & & 41.1 & 24.8 & 15.1 \\
\hline 11 & & 76.3 & 8.1 & 56.1 \\
\hline
\end{tabular}

We altered the number of $\mathrm{sp}^{3}$ carbons between the two phenyl rings and evaluated the mediated oxidation of bibenzyl (1), 1,3-diphenylpropane (8) (three $\mathrm{sp}^{3}$ carbons) and 1,4-diphenylbutane (11) (four $\mathrm{sp}^{3}$ carbons). While the conversion of the substrates increased with increasing number of carbons, the selectivity of $\mathrm{C}-\mathrm{C}$ bond cleavage decreased.
In turn, the selectivity of $\mathrm{C}-\mathrm{H}$ bond oxygenation increased with the number of carbons. Additionally, we detected products from $\mathrm{C}_{\text {aryl }}-\mathrm{C}_{\text {benzyl }}$ bond cleavage for (8) (phenol; Figures S16, S17 and S19) and (11) (phenol and benzenebutanal; Figures S16 S20, and S21). Furthermore, products resulting from intramolecular cyclization were 
also observed for (8) (1,2-diphenylcyclopropane; Figures S16, S18, and S19) and (11) (1,2,3,4-tetrahydro-1-phenylnaphthalene; Figures S16, S20, and S21). We hypothesize that the product distribution is determined by the relative bond strength of $\mathrm{C}-\mathrm{C}$ and $\mathrm{C}-\mathrm{H}$ bonds. Table S7 lists the calculated BDEs for these bonds in (1), (8) and (11). ${ }^{44,45}$ Specifically, the weak $C_{\text {benzyl }}-C_{\text {benzyl }}$ bond of $\mathbf{1}$ led to its significantly higher selectivity of C-C bond cleavage compared to the other two substrates. The reason why (8) had a higher selectivity of $\mathrm{C}-\mathrm{C}$ bond cleavage despite its larger $\mathrm{C}-\mathrm{C}$ BDEs than (11) could be attributed to the stronger $\mathrm{C}-\mathrm{H}$ bonds of (8) compared to those of (11).

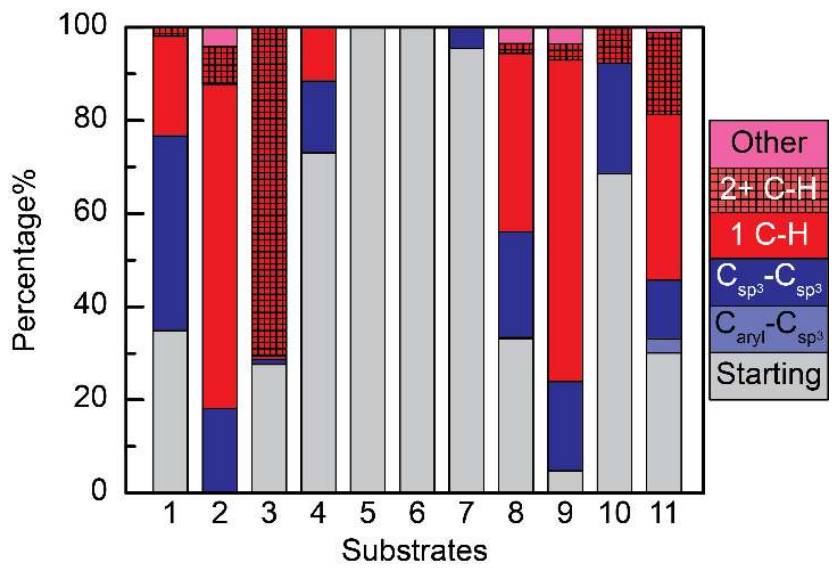

Figure 4. Products distribution of NHPI-mediated oxidation.

Substituents on the benzylic carbon, namely substrates with one -OH group (1,2-diphenylethanol (2), Table 2, Figures 4, S16, S22-S24) or two -OH groups (meso-hydrobenzoin (3), Table 2, Figures 4, S16, S25-S27), also affected the rates of NHPI-mediated oxidation. Since the direct oxidation of meso-hydrobenzoin onsets at $1.1 \mathrm{~V} \mathrm{vs} \mathrm{Ag} / \mathrm{AgCl}$ (Figure S13a), the bulk electrolysis was terminated when the potential reached $1.1 \mathrm{~V}$ (Figure S14b). The conversions for these two substrates were higher than that of $\mathbf{1}$, while the selectivity to $\mathrm{C}-\mathrm{C}$ bond cleavage decreased dramatically. After the electrolysis of (2), we detected a product of $N$-(1,2diphenylethyl)acetamide (Figure S24) that is formed by acetonitrile solvolysis. ${ }^{46}$ It was unclear, however, whether the presence of $-\mathrm{OH}$ groups promotes HAT of the $\alpha \mathrm{C}-\mathrm{H}$ or $-\mathrm{OH}$ is oxidized by PINO. Accordingly, we substituted the two benzylic $\mathrm{C}-\mathrm{H}$ hydrogen atoms in (3) by two methyl groups and performed bulk electrolysis on the substrate 2,3-diphenyl-2,3-butanediol (7) (Table 2, Figures 4, S16, S28-S30). Similar to (3), the direct oxidation of 7 onsets at $1.2 \mathrm{~V}$ vs $\mathrm{Ag} / \mathrm{AgCl}$, and therefore, requires the threshold potential of bulk electrolysis to be set at $1.2 \mathrm{~V}$ (Figures S13b and S14f). Notably, minimal products were generated. The results indicate that the alcohol -OH group cannot be oxidized by PINO due to its large BDE (Table S7), ${ }^{44,45}$ which is consistent with previous reports. ${ }^{47}$ Therefore, the presence of $\mathrm{OH}$ groups facilitates the HAT of the $\alpha \mathrm{C}-\mathrm{H}$ by weakening the $\alpha$ C-H bond (Table S7). ${ }^{44,45}$

Similarly, methyl or carbonyl groups cannot be oxidized by PINO. For benzil (5) (Table 2, Figures 4, S16, S31S32) and 2,3-dimethyl-2,3-diphenylbutane (6) (Table 2, Figures 4, S16, S33-S34), no conversion was observed after NHPI-mediated bulk electrolysis. Further, as shown in Table 2 and Figure 4, the carbonyl-containing substrate 1,2-diphenylethanone (4) (Figures S16, S35-S36) generated much lower conversion and product selectivity. Given that the benzylic C-H BDE of (4) (Table S7) is slightly smaller than that of bibenzyl (1), we credit the decreased conversion of (4) to the reduced number of available benzylic $\mathrm{C}-\mathrm{H}$ bonds.

Similar substituent studies on the family of 1,3-diphenylpropane were also performed. Compared to (8), 1,3-diphenyl-1-propanol (9) (Table 2 and Figures 6, S16, S37S38) resulted in a significantly higher conversion and dominating product selectivity toward the $\mathrm{C}-\mathrm{H}$ oxygenation pathway. Analogous to (2), we also detected the product formed by acetonitrile solvolysis, $N$-(1,3-diphenylpropyl)acetamide. On the other hand, the substrate 1,3-diphenyl-1-propanone (10) (Table 2, Figures 4, S16, S39-S40) resulted in a lower conversion and a lower selectivity of $\mathrm{C}$ $\mathrm{H}$ oxygenation products, while the selectivity of $\mathrm{C}-\mathrm{C}$ bond cleavage was much higher than that of (8). We attribute the improved selectivity to the relatively weak $\mathrm{C}_{\text {center- }} \mathrm{C}_{\text {benzyl }}$ bond of (10) compared to (8) (Table S7). ${ }^{44,45}$ The results of 1,3-diphenylpropane family substrates agree with the conclusions obtained from the bibenzyl family substrates that 1) the -OH group facilitates the benzylic $\mathrm{C}-\mathrm{H}$ HAT, and 2) the carbonyl group suppresses the PINO oxidation conversion.

Mediated oxidation of oligomeric styrene. We explored the NHPI-mediated oxidation of oligomeric styrene (OS) with a number average molecular weight $\left(M_{\mathrm{n}}\right)$ of $510 \mathrm{Da}$ and a narrow dispersity of 1.05. Details of the oligomers preparation and characterizations can be found in the SI (Figure S41-S43 for GPC and NMR results).

CV studies confirmed that the oligomeric styrene, denoted as $\mathrm{OS}_{510}$, underwent NHPI-mediated oxidation, and the onset potential of the mediated oxidation was $1.01 \mathrm{~V}$ less positive than that of the direct oxidation (Figure S44). Notably, there was a small reductive feature in the cathodic sweep, suggesting that the PINO formed in the anodic sweep was not completely consumed by $\mathrm{OS}_{510}$. Therefore, in the bulk electrolysis, we applied a constant current of $1 \mathrm{~mA}$ instead of $2 \mathrm{~mA}$ to slow down the generation and the accumulation of PINO and to suppress PINO decomposition. All other standard bulk electrolysis conditions were employed. A representative chronopotentiometry is shown in Figure S45. The oxidation progress was monitored by GC-MS (Figure S46-S48) and GC-FID (Figure S49). Here we defined a parameter "unit charge $q\left(\mathrm{~F} \mathrm{~mol}^{-1}\right)$ " to quantify the number of electrons passed per styrene unit:

$$
q=\frac{Q}{F\left(\frac{m}{104}\right)}
$$

$Q$ (C) is the charge passed in electrolysis, $F$ (96485 $\mathrm{C} \mathrm{mol}^{-1}$ ) is the Faradaic constant, $m(\mathrm{~g})$ is the weight of $\mathrm{OS}_{510}$ added to the electrochemical cell, and $104\left(\mathrm{~g} \mathrm{~mol}^{-1}\right)$ is the molecular weight of one styrene unit. Additional NHPI and pyridine were added once the potential reached $1.5 \mathrm{~V}$ vs $\mathrm{Ag} / \mathrm{AgCl}$ to continue the oxidation.

Figure 5 and Table S8 present the mass yields of oxidation products consisting of zero to five phenyl rings $\left(\mathrm{Ph}_{0}\right.$ 5). Products with more than five phenyl rings were not detectable by GC-FID due to their high boiling points. The yields of $\mathrm{Ph}_{0-1}$ products increased with increasing unit charge, from $3.1 \%(q=0.57)$ to $13.6 \%(q=2.28)$, indicating the oxidative cleavage of $\mathrm{C}-\mathrm{C}$ bonds. On the other hand, the 
yields of longer chain products $\left(\mathrm{Ph}_{3-5}\right)$ generally decreased with increasing $q$ due to their further oxidation. The simultaneous formation of these products could also lead to an initial rise in the yields at small $q$ values ( $\mathrm{Ph}_{3}$ and $\left.\mathrm{Ph}_{5}\right)$. The yields of $\mathrm{Ph}_{2}$ products only oscillated a little across the oxidation process, suggesting a balance between their formation and further oxidation. The yield of all detected products decreased from $29.4 \%(q=0.57)$ to $16.7 \%(q=2.28)$ perhaps because some products were overoxidized, e.g., phenol to ring-opened products.

Based on the product distribution, we propose an oxidation pathway (Scheme 2). Taking a tetramer styrene as an example, the initial step is HAT from a benzylic $\mathrm{C}-\mathrm{H}$, affording a benzylic carbon radical. Upon being captured by $\mathrm{O}_{2}$, a peroxy radical is formed which decomposes into the products. The HAT can take place at either an ending styrene (red branch) or a center one (blue branch), which leads to different peroxy decomposition pathways. The products can undergo further mediated oxidation. Besides, the benzylic radical can couple with a PINO radical or form a $\mathrm{C}=\mathrm{C}$ double bond, leading to products other than C-C cleavage or $\mathrm{C}-\mathrm{H}$ oxygenation. a)

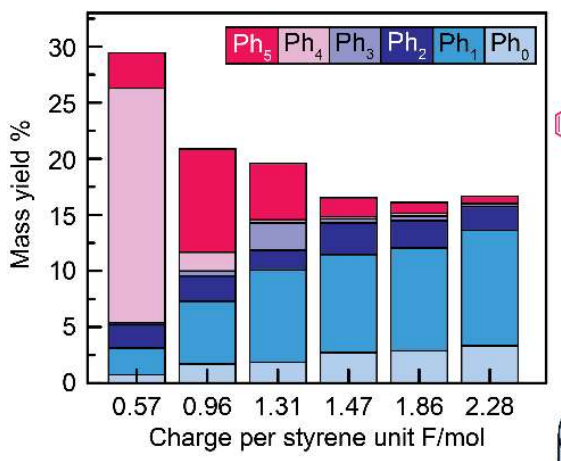

b)

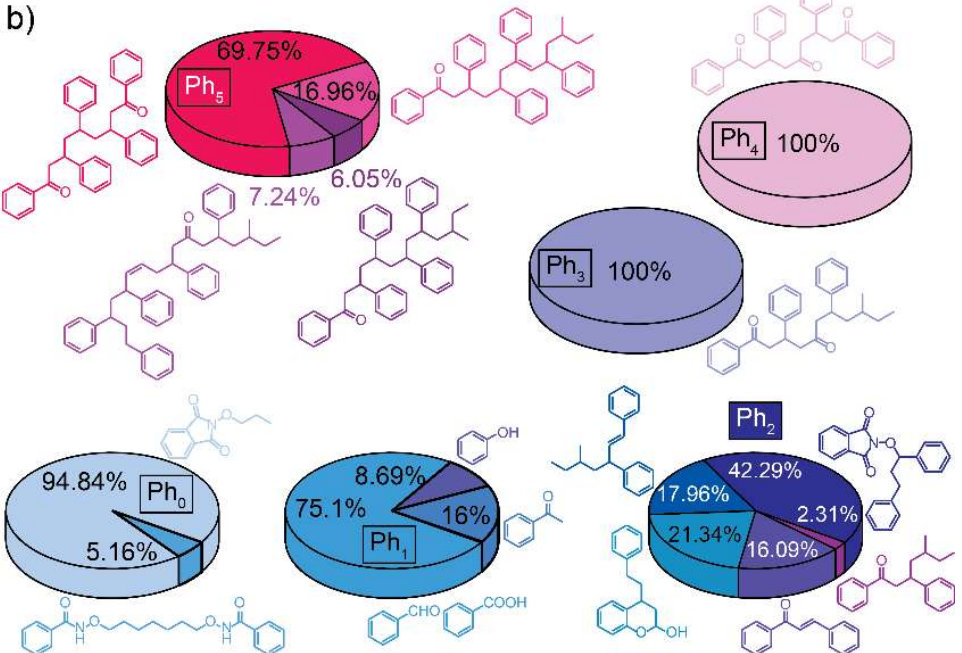

Figure 5. For the mediated oxidation of $\mathrm{OS}_{510}$, (a) the mass yields and (b) the distribution of products consisting of zero to five phenyl rings $\left(\mathrm{Ph}_{0-5}\right.$ ) depend on the charge passed to each styrene unit in average (unit charge $q$ ). Products were quantified by GC-FID. The product distribution was based on the results at $q=2.28$.

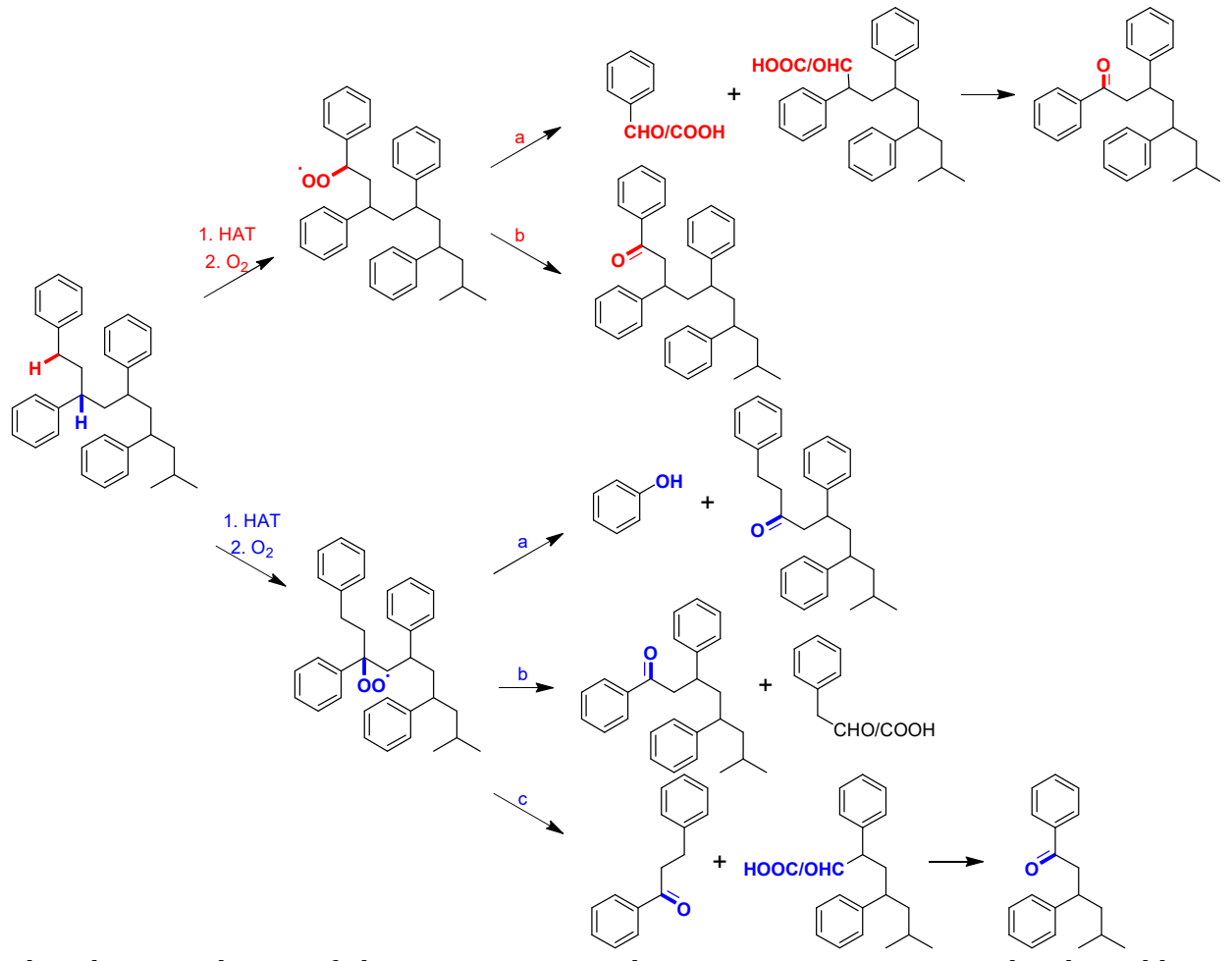

Scheme 2. Proposed oxidation pathways of oligomeric styrene, taking a tetramer as an example. The red branch depicts the HAT from an ending styrene unit, and the blue one for the HAT from a center styrene unit. 
a)

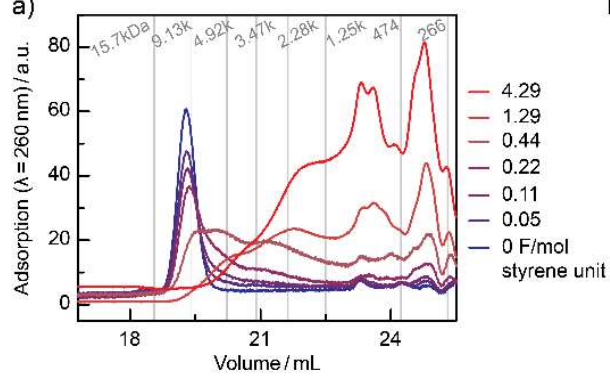

b)

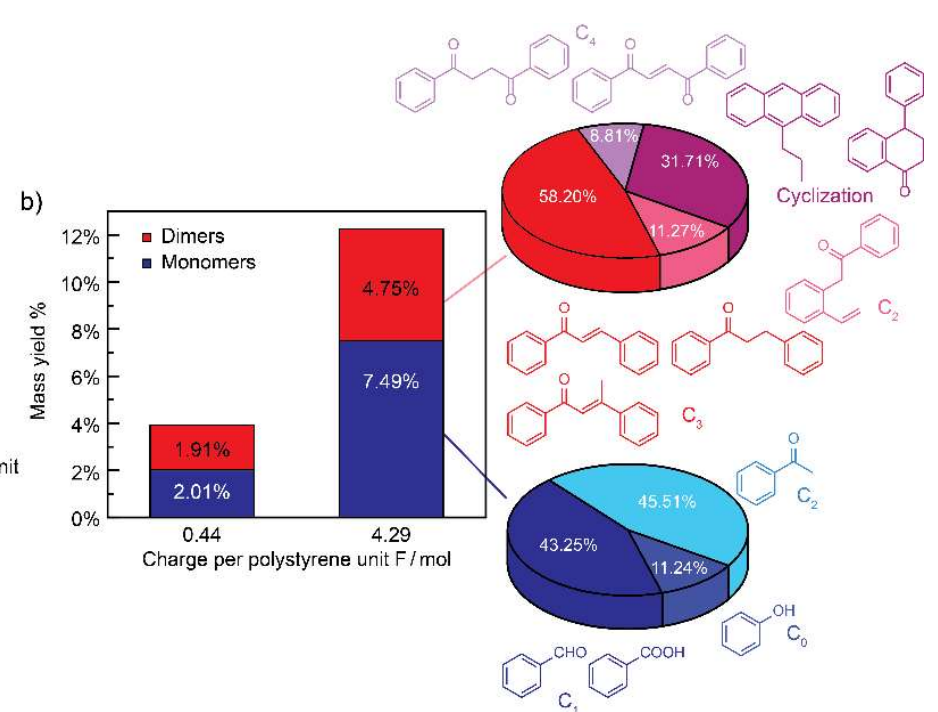

Figure 6. (a) GPC results of NHPI-mediated PS oxidation with increasing unit charge. (b) Monomeric and dimeric products distribution after the bulk electrolysis of PS.

Polystyrene depolymerization. We employed the NHPI-mediated oxidation strategy to depolymerize PS as a proof-of-concept. The PS substrate used was an analytical standard for gel permeation chromatography (GPC) $(10,000 \mathrm{Da})$ with a low dispersity (1.06). Since PS has a low solubility in acetonitrile, we performed the electrolysis in acetone. For the bulk electrolysis, a constant current of $1 \mathrm{~mA}$ was applied (Figure $\mathbf{S 5 0}$ depicts a representative chronopotentiometry trace), same as the oxidation of the $\mathrm{OS}_{510}$ oligomeric styrene.

The depolymerization progress was monitored by GPC. Additional NHPI and pyridine were added once the potential reached $1.5 \mathrm{~V}$ vs $\mathrm{Ag} / \mathrm{AgCl}$ to continue the depolymerization until all of the starting PS was converted. To measure the molecular weight of the products by GPC, we constructed a calibration curve between the molecular weight of the peak maxima and eluent volume (Figure S43a) using a number of standard polymers. The GPC results are shown in Figure 6a. Prior to electrolysis, the PS substrate had a peak molecular weight of $\sim 10,000 \mathrm{Da}$. With increasing charge passed, the peak at $\sim 10,000$ Da decreased and new peaks at lower molecular weight appeared and grew with reaction time. When the unit charge exceeded $1.29 \mathrm{~F} \mathrm{~mol}^{-1}$, meaning that in average, more than 1.29 electrons were transferred to one styrene unit, all of the starting PS was converted into smaller molecules.

Monomeric (one phenyl ring) and dimeric (two phenyl rings) products of PS depolymerization were identified and quantified by GC-MS (Figure S51) and GC-FID (Figure S52). The results are illustrated in Figure $\mathbf{6 b}$. At $q=0.44$, the monomer yield was $2.01 \%$ and the dimer yield was $1.91 \%$. When more electrons were transferred, at $q=4.29$, the monomer yield increased to $7.49 \%$ and the dimer yield to $4.75 \%$. Three categories of monomers were detected in which the phenyl ring has zero $\left(\mathrm{C}_{0}\right)$, one $\left(\mathrm{C}_{1}\right)$, or two carbons $\left(\mathrm{C}_{2}\right)$ attached to it. Consistent with the small molecule oxidation results, the $\mathrm{C}_{\mathrm{sp} 3}-\mathrm{C}_{\mathrm{sp} 3}$ bond cleavage $\left(\mathrm{C}_{1}\right.$ and $\mathrm{C}_{2}$ monomers) had a larger yield than the $\mathrm{C}_{\text {aryl }}-\mathrm{C}_{\text {benzyl }}$ bond cleavage $\left(\mathrm{C}_{0}\right)$. For the dimeric products, three categories of products were identified that differ in the number of carbon atoms between the two phenyl rings: two $\left(\mathrm{C}_{2}\right)$, three $\left(\mathrm{C}_{3}\right)$, and four carbons $\left(\mathrm{C}_{4}\right)$, plus a fourth category of cyclic structures. $\mathrm{C}_{3}$ molecules were the major dimeric products, in agreement with the repeating unit of PS where the two phenyl rings are separated by three $\mathrm{sp}^{3}$ carbons.

There remain many challenges to achieve effective depolymerization of PS waste. For example, the slow diffusion and high viscosity of the PS in solution limits the rate of HAT from PS to PINO. ${ }^{48-50}$ Strategies to facilitate mass transfer, such as increasing the operational temperature, using mixed solvents, and vigorous stirring may improve PS conversion. Additionally, PS plastic contains a number of additives such as metals, metal oxides, pigments, dyes, thermal stabilizers, photo-stabilizers, and other polymers (e.g., acrylonitrile butadiene styrene terpolymer, ABS), ${ }^{51-53}$ which could significantly impact the electrochemical oxidation reactivity. Furthermore, systematic characterization techniques need to be established to identify and quantify the full spectrum of the oxidation products. In particular, the oligomer products cannot be analyzed by GC-FID or GC-MS. We noted that the mediated oxidation affords oligomer products spanning the whole range of molecular weights from 300-5,000 Da according to GPC, which are challenging to analyze by NMR or LC-MS. Future work will focus on finding solutions to these challenges.

\section{CONCLUSION}

Here we established an electrochemical method to cleave inert $\mathrm{C}_{\mathrm{sp} 3}-\mathrm{C}_{\mathrm{sp} 3}$ bonds at room temperature and ambient pressure. We showed that NHPI functions as a redox mediator that upon oxidation is converted into the PINO radical which initiates HAT reactions with benzylic $\mathrm{C}-\mathrm{H}$. The resulting benzylic carbon radical is readily captured by molecular oxygen to afford a peroxy radical that decomposes in a bifurcated pathway which leads to either $\mathrm{C}-\mathrm{C}$ bond cleavage or $\mathrm{C}-\mathrm{H}$ bond oxygenation products. The mediated oxidation approach successfully cleaved C-C bond of model compounds such as bibenzyl, 1,3-diphenylpropane, 1,4-diphenylbutane, and their derivatives. Additionally, oligomeric styrene $\left(M_{\mathrm{n}}=510 \mathrm{Da}\right)$ were converted into oxygenated products consisting of zero or one phenyl ring at a yield 
of $13.6 \%$. As a proof-of-concept, we employed NHPI to mediate the oxidative depolymerization of PS $(10,000 \mathrm{Da})$ and achieved a yield of monomers and dimers of $12 \%$.

The NHPI-mediated oxidation strategy demonstrates the great potential of electrocatalysis in activating inert chemical bonds under mild conditions. Given the wide variety of redox mediators, this study opens the door to employing renewable electricity and targeted redox mediators to catalyze challenging chemical transformations. Future studies will focus on engineering the redox mediator to improve its stability in order to boost the conversion and product selectivity. Additionally, strategies to immobilize the redox mediators onto a support or to develop heterogeneous mediators will facilitate the product separation and purification processes, especially for large-scale applications.

\section{ASSOCIATED CONTENT}

\section{Supporting Information.}

Complete experimental details, GC-MS data, GC-FID data, HPLC data, GPC data, chronopotentiometry results. This information is available free of charge on the ACS Publication website at DOI: XXX-XX.

\section{AUTHOR INFORMATION}

\section{Corresponding Author \\ *yroman@mit.edu}

\section{Notes}

\section{ACKNOWLEDGMENT}

We thank Griffin Drake, Thejas Wesley, Dr. Julie Rorrer, Dr. Ydna Questell-Santiago, and other members of the BOTTLE Consortium for helpful discussions. Funding was provided by the U.S. Department of Energy, Office of Energy Efficiency and Renewable Energy, Advanced Manufacturing Office (AMO) and Bioenergy Technologies Office (BETO). This work was performed as part of the BioOptimized Technologies to keep Thermoplastics out of Landfills and the Environment (BOTTLE) Consortium and was supported by AMO and BETO under Contract DE-AC36-08G028308 with the National Renewable Energy Laboratory (NREL), operated by Alliance for Sustainable Energy, LLC. The BOTTLE Consortium includes members from MIT and Colorado State University, funded under Contract DEAC36-08G028308 with NREL. The views expressed in the article do not necessarily represent the views of the DOE or the U.S. Government. This work was also supported by Eni S.p.A. through the MIT Energy Initiative.

\section{REFERENCES}

(1) Allpress, C. J.; Berreau, L. M. Oxidative Aliphatic CarbonCarbon Bond Cleavage Reactions. Coord. Chem. Rev. 2013, 257 (21-22), 3005-3029.

(2) Wang, W.; Wang, M.; Li, X.; Cai, L.; Shi, S. Q.; Duan, C.; Ni, Y. Microwave-Assisted Catalytic Cleavage of $\mathrm{C}-\mathrm{C}$ Bond in Lignin Models by Bifunctional Pt/CDC-SiC. ACS Sustain. Chem. Eng. 2020, 8 (1), 38-43.

(3) Zakzeski, J.; Bruijnincx, P. C. A.; Jongerius, A. L.; Weckhuysen, B. M. The Catalytic Valorization of Lignin for the Production of Renewable Chemicals. Chem. Rev. 2010, 110 (6), 35523599.

(4) Martín, A. J.; Mondelli, C.; Jaydev, S. D.; Pérez-Ramírez, J.
Catalytic Processing of Plastic Waste on the Rise. Chem 2021, $O(0)$.

(5) Rahimi, A. R.; Garciá, J. M. Chemical Recycling of Waste Plastics for New Materials Production. Nat. Rev. Chem. 2017, $1(6), 1-11$.

(6) Vollmer, I.; Jenks, M. J. F.; Roelands, M. C. P.; White, R. J.; van Harmelen, T.; de Wild, P.; van der Laan, G. P.; Meirer, F.; Keurentjes, J. T. F.; Weckhuysen, B. M. Beyond Mechanical Recycling: Giving New Life to Plastic Waste. Angew. Chemie Int. Ed. 2020, 59 (36), 15402-15423.

(7) Serrano, D. P.; Aguado, J.; Escola, J. M. Developing Advanced Catalysts for the Conversion of Polyolefinic Waste Plastics into Fuels and Chemicals. ACS Catal. 2012, 2 (9), 1924-1941.

(8) Rorrer, J. E.; Beckham, G. T.; Román-Leshkov, Y. Conversion of Polyolefin Waste to Liquid Alkanes with Ru-Based Catalysts under Mild Conditions. JACS Au 2021, 1 (1), 8-12.

(9) Wiles, D. M.; Scott, G. Polyolefins with Controlled Environmental Degradability. Polym. Degrad. Stab. 2006, 91 (7), 1581-1592.

(10) Jun, C. H. Transition Metal-Catalyzed Carbon-Carbon Bond Activation. Chem. Soc. Rev. 2004, 33 (9), 610-618.

(11) Liu, H.; Feng, M.; Jiang, X. Unstrained Carbon-Carbon Bond Cleavage. Chem. - An Asian J. 2014, 9 (12), 3360-3389.

(12) Sivaguru, P.; Wang, Z.; Zanoni, G.; Bi, X. Cleavage of CarbonCarbon Bonds by Radical Reactions. Chem. Soc. Rev. 2019, 48 (9), 2615-2656.

(13) Kondo, T.; Mitsudo, T.-A. Ruthenium-Catalyzed Reconstructive Synthesis of Functional Organic Molecules via Cleavage of Carbon-Carbon Bonds. Chem. Lett. 2005, 34 (11), 1462-1467.

(14) Terao, Y.; Wakui, H.; Satoh, T.; Miura, M.; Nomura, M. Palladium-Catalyzed Arylative Carbon-Carbon Bond Cleavage of $\alpha, \alpha$-Disubstituted Arylmethanols. J. Am. Chem. Soc. 2001, 123 (42), 10407-10408.

(15) Rybtchinski, B.; Milstein, D. Metal Insertion into C-C Bonds in Solution. Angew. Chemie Int. Ed. 1999, 38 (7), 870-883.

(16) Ellis, L. D.; Orski, S. V.; Kenlaw, G. A.; Norman, A. G.; Beers, K. L.; Román-Leshkov, Y.; Beckham, G. T. Tandem Heterogeneous Catalysis for Polyethylene Depolymerization via an Olefin-Intermediate Process. ACS Sustain. Chem. Eng. 2021, 9 (2), 623-628.

(17) Zhang, F.; Zeng, M.; Yappert, R. D.; Sun, J.; Lee, Y. H.; LaPointe, A. M.; Peters, B.; Abu-Omar, M. M.; Scott, S. L. Polyethylene Upcycling to Long-Chain Alkylaromatics by Tandem Hydrogenolysis/Aromatization. Science. 2020, 370 (6515), 437-441.

(18) Celik, G.; Kennedy, R. M.; Hackler, R. A.; Ferrandon, M.; Tennakoon, A.; Patnaik, S.; Lapointe, A. M.; Ammal, S. C.; Heyden, A.; Perras, F. A.; et al. Upcycling Single-Use Polyethylene into High-Quality Liquid Products. ACS Cent. Sci. 2019, 5 (11), 1795-1803.

(19) Kanbur, U.; Zang, G.; Paterson, A. L.; Chatterjee, P.; Hackler, R. A.; Delferro, M.; Slowing, I. I.; Perras, F. A.; Sun, P.; Sadow, A. D. Catalytic Carbon-carbon Bond Cleavage and CarbonElement Bond Formation Give New Life for Polyolefins as Biodegradable Surfactants. Chem 2021, $O$ (0).

(20) Partenheimer, W. Valuable Oxygenates by Aerobic Oxidation of Polymers Using Metal/Bromide Homogeneous Catalysts. Catal. Today 2003, 81 (2), 117-135.

(21) Adeli, Y.; Huang, K.; Liang, Y.; Jiang, Y.; Liu, J.; Song, S.; Zeng, C. C.; Jiao, N. Electrochemically Oxidative C-C Bond Cleavage of Alkylarenes for Anilines Synthesis. ACS Catal. 2019, 9 (3), 2063-2067.

(22) Khan, F. N.; Jayakuma, R.; Pillai, C. N. Electrocatalytic Oxidative Cleavage by Electrogenerated Periodate. J. Mol. Catal. A Chem. 2003, 195 (1-2), 139-145.

(23) Rafiee, M.; Alherech, M.; Karlen, S. D.; Stahl, S. S. Electrochemical Aminoxyl-Mediated Oxidation of Primary Alcohols in Lignin to Carboxylic Acids: Polymer Modification and Depolymerization. J. Am. Chem. Soc. 2019, 141 (38), 15266-15276.

(24) Zollinger, D.; Griesbach, U.; Pütter, H.; Comninellis, C. Electrochemical Cleavage of 1,2-Diphenylethanes at BoronDoped Diamond Electrodes. Electrochem. commun. 2004, 6 
(6), 605-608.

(25) Kawamata, Y.; Yan, M.; Liu, Z.; Bao, D. H.; Chen, J.; Starr, J. T.; Baran, P. S. Scalable, Electrochemical Oxidation of Unactivated C-H Bonds. J. Am. Chem. Soc. 2017, 139 (22), 7448-7451.

(26) Shi, S. H.; Liang, Y.; Jiao, N. Electrochemical Oxidation Induced Selective C-C Bond Cleavage. Chem. Rev. 2021, 121 (1), 485505 .

(27) Nutting, J. E.; Rafiee, M.; Stahl, S. S. Tetramethylpiperidine NOxyl (TEMPO), Phthalimide N-Oxyl (PINO), and Related NOxyl Species: Electrochemical Properties and Their Use in Electrocatalytic Reactions. Chem. Rev. 2018, 118 (9), 48344885.

(28) Wang, F.; Stahl, S. S. Electrochemical Oxidation of Organic Molecules at Lower Overpotential: Accessing Broader Functional Group Compatibility with Electron-Proton Transfer Mediators. Acc. Chem. Res. 2020, 53 (3), 561-574.

(29) Francke, R.; Little, R. D. Redox Catalysis in Organic Electrosynthesis: Basic Principles and Recent Developments. Chem. Soc. Rev. 2014, 43 (8), 2492-2521.

(30) Rafiee, M.; Wang, F.; Hruszkewycz, D. P.; Stahl, S. S. NHydroxyphthalimide-Mediated Electrochemical Iodination of Methylarenes and Comparison to Electron-Transfer-Initiated C-H Functionalization. J. Am. Chem. Soc. 2018, 140 (1), 22-25.

(31) Coseri, S. Phthalimide- $N$-oxyl (PINO) Radical, a Powerful Catalytic Agent: Its Generation and Versatility Towards Various Organic Substrates. Catal. Rev. 2009, 51 (2), 218-292.

(32) Yang, G.; Ma, Y.; Xu, J. Biomimetic Catalytic System Driven by Electron Transfer for Selective Oxygenation of Hydrocarbon. J. Am. Chem. Soc. 2004, 126 (34), 10542-10543.

(33) Tateno, H.; Miseki, Y.; Sayama, K. PINO/NHPI-Mediated Selective Oxidation of Cycloalkenes to Cycloalkenones: Via a Photo-Electrochemical Method. Chem. Commun. 2019, 55 (63), 9339-9342.

(34) Barbieri, A.; Lanzalunga, O.; Lapi, A.; Di Stefano, S. NHydroxyphthalimide: A Hydrogen Atom Transfer Mediator in Hydrocarbon Oxidations Promoted by Nonheme Iron(IV)Oxo Complexes. J. Org. Chem. 2019, 84 (21), 13549-13556.

(35) Rafiee, M.; Karimi, B.; Alizadeh, S. Mechanistic Study of the Electrocatalytic Oxidation of Alcohols by TEMPO and NHPI ChemElectroChem 2014, 1 (2), 455-462.

(36) Savéant, J. M. Elements of Molecular and Biomolecular Electrochemistry: An Electrochemical Approach to Electron Transfer Chemistry; John Wiley and Sons: Hoboken, NJ, USA, 2006.

(37) Amorati, R.; Lucarini, M.; Mugnaini, V.; Pedulli, G. F.; Minisci, F.; Recupero, F.; Fontana, F.; Astolfi, P.; Greci, L. Hydroxylamines as Oxidation Catalysts: Thermochemical and Kinetic Studies. J. Org. Chem. 2003, 68 (5), 1747-1754.

(38) Koshino, N.; Cai, Y.; Espenson, J. H. Kinetic Study of the Phthalimide N-Oxyl (PINO) Radical in Acetic Acid. Hydrogen Abstraction from C-H Bonds and Evaluation of $\mathrm{O}-\mathrm{H}$ Bond Dissociation Energy of N-Hydroxyphthalimide. J. Phys. Chem.
A 2003, 107 (21), 4262-4267.

(39) Kushch, O.; Kushch, O.; Hordieieva, I.; Novikova, K.; Litvinov, Y.; Kompanets, M.; Kompanets, M.; Shendrik, A.; Opeida, I.; Opeida, I. Kinetics of N-Oxyl Radicals' Decay. J. Org. Chem. 2020, 85 (11), 7112-7124.

(40) Horn, E. J.; Rosen, B. R.; Chen, Y.; Tang, J.; Chen, K.; Eastgate, M. D.; Baran, P. S. Scalable and Sustainable Electrochemical Allylic C-H Oxidation. Nature 2016, 533 (7601), 77-81.

(41) Krylov, I. B.; Paveliev, S. A.; Budnikov, A. S.; Terent'ev, A. 0 Oxime Radicals: Generation, Properties and Application in Organic Synthesis. Beilstein J. Org. Chem. 2020, 16 (1), 12341276.

(42) Reich, H. J. What's Going on with These Lithium Reagents? J. Org. Chem. 2012, 77 (13), 5471-5491.

(43) Annunziatini, C.; Gerini, M. F.; Lanzalunga, 0.; Lucarini, M. Aerobic Oxidation of Benzyl Alcohols Catalyzed by Aryl Substituted N-Hydroxyphthalimides. Possible Involvement of a Charge-Transfer Complex. J. Org. Chem. 2004, 69 (10), 3431-3438.

(44) St. John, P. C.; Guan, Y.; Kim, Y.; Kim, S.; Paton, R. S. Prediction of Organic Homolytic Bond Dissociation Enthalpies at near Chemical Accuracy with Sub-Second Computational Cost. Nat. Commun. 2020, 11 (1), 1-12.

(45) St. John, P. C.; Guan, Y.; Kim, Y.; Etz, B. D.; Kim, S.; Paton, R. S. Quantum Chemical Calculations for over 200,000 Organic Radical Species and 40,000 Associated Closed-Shell Molecules. Sci. Data 2020, 7 (1), 1-6.

(46) Camaioni, D. M.; Franz, J. A. Carbon-Hydrogen vs. CarbonCarbon Bond Cleavage of 1,2-Diarylethane Radical Cations in Acetonitrile-Water. J. Org. Chem. 1984, 49 (9), 1607-1613.

(47) D'Acunzo, F.; Baiocco, P.; Fabbrini, M.; Galli, C.; Gentili, P. The Radical Rate-Determining Step in the Oxidation of Benzyl Alcohols by Two N-OH-Type Mediators of Laccase: The Polar N-Oxyl Radical Intermediate. New J. Chem. 2002, 26 (12), 1791-1794.

(48) Li, S. U.; Gainer, J. L. Diffusion in Polymer Solutions. Ind. Eng. Chem. Fundam. 1968, 7 (3), 433-440.

(49) Urakawa, O.; Swallen, S. F.; Ediger, M. D.; Von Meerwall, E. D. Self-Diffusion and Viscosity of Low Molecular Weight Polystyrene over a Wide Temperature Range. Macromolecules 2004, 37 (4), 1558-1564.

(50) Rauch, J.; Köhler, W. Collective and Thermal Diffusion in Dilute, Semidilute, and Concentrated Solutions of Polystyrene in Toluene. J. Chem. Phys. 2003, 119 (22), 11977-11988.

(51) Turner, A. Foamed Polystyrene in the Marine Environment: Sources, Additives, Transport, Behavior, and Impacts. Environ. Sci. Technol. 2020, 54 (17), 10411-10420.

(52) Jakab, E.; Uddin, M. A.; Bhaskar, T.; Sakata, Y. Thermal Decomposition of Flame-Retarded High-Impact Polystyrene. J. Anal. Appl. Pyrolysis 2003, 68-69, 83-99.

(53) Yousif, E.; Haddad, R. Photodegradation and Photostabilization of Polymers, Especially Polystyrene: Review. Springerplus 2013, 2 (1), 398-398. 
TOC Graphic:
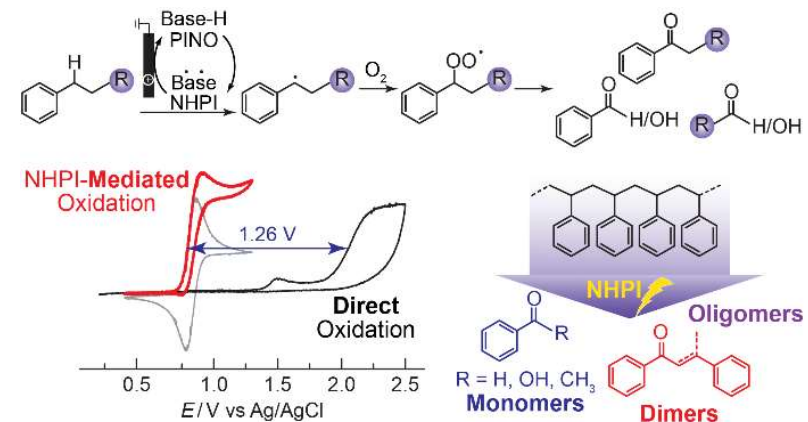